\title{
Microstructural White Matter Abnormalities in the Dorsal Cingulum of Adolescents with IBS
}

\author{
(1) Catherine S. Hubbard, ${ }^{1,2,3,4,5}$ - $L i n o$ Becerra, ${ }^{1,2,3}$ Nicole Heinz, ${ }^{6}$ Allison Ludwick, ${ }^{1}$ Tali Rasooly, ${ }^{1}$ \\ Anastasia Yendiki, ${ }^{4,5}$ Rina $\mathrm{Wu}^{6}{ }^{6}$ Neil L. Schechter, ${ }^{2,3}$ Samuel Nurko, ${ }^{6,7^{*}}$ and David Borsook ${ }^{1,2,3}$
}

DOI:http://dx.doi.org/10.1523/ENEURO.0354-17.2018

${ }^{1}$ Center for Pain and the Brain, Boston Children's Hospital, Waltham, MA, ${ }^{2}$ Department of Anesthesiology, Perioperative and Pain Medicine, Boston Children's Hospital, Boston, MA, ${ }^{3}$ Department of Anaesthesia, Harvard Medical School, Boston, MA, ${ }^{4}$ Athinoula A. Martinos Center for Biomedical Imaging, Massachusetts General Hospital, Charlestown, MA, ${ }^{5}$ Department of Radiology, Harvard Medical School, Boston, MA, ${ }^{6}$ Division of Gastroenterology, Hepatology and Nutrition, Center for Motility and Functional Gastrointestinal Disorders, Boston Children's Hospital, Boston, MA, and ${ }^{7}$ Department of Pediatrics, Harvard Medical School, Boston, MA

\begin{abstract}
Alterations in fractional anisotropy (FA) have been considered to reflect microstructural white matter (WM) changes in disease conditions; however, no study to date has examined WM changes using diffusion tensor imaging (DTI) in adolescents with irritable bowel syndrome (IBS). The objective of the present study was two-fold: (1) to determine whether differences in FA, and other non-FA metrics, were present in adolescents with IBS compared to healthy controls using whole-brain, region of interest (ROI)-restricted tract-based spatial statistics (TBSS) and canonical ROI DTI analyses for the cingulum bundle, and (2) to determine whether these metrics were related to clinical measures of disease duration and pain intensity in the IBS group. A total of 16 adolescents with a Rome III diagnosis of IBS (females = 12; mean age = 16.29, age range: $11.96-18.5$ years) and 16 age- and gender-matched healthy controls (females $=12$; mean age $=16.24$; age range: 11.71-20.32 years) participated in this study. Diffusion-weighted images were acquired using a Siemens 3-T Trio Tim Syngo MRI scanner with a 32-channel head coil. The ROI-restricted TBSS and canonical ROI-based DTI analyses revealed that adolescents with IBS showed decreased FA in the right dorsal cingulum bundle compared to controls. No relationship between FA and disease severity measures was found. Microstructural WM alterations in the right dorsal cingulum bundle in adolescents with IBS may reflect a premorbid brain state or the emergence of a disease-driven process that results from complex changes in pain- and affect-related processing via spinothalamic and corticolimbic pathways.
\end{abstract}

Key words: abdominal pain; DTI; functional GI disorders; IBS; pediatrics

\section{Significance Statement}

In the present study we observed white matter (WM) abnormalities indexed by decreased fractional anisotropy (FA) in the right dorsal cingulum in adolescents with irritable bowel syndrome (IBS) compared to a healthy cohort. However, this decrease in WM FA was not related to disease severity measures. These findings represent the first report of WM brain changes in an adolescent population with IBS.

\section{Introduction}

Irritable bowel syndrome (IBS) is a common functional gastrointestinal disorder (FGID) affecting both adults and children (Longstreth et al., 2006). Like many other chronic

Received October 17, 2017; accepted June 7, 2018; First published July 27, 2018.

The authors declare no competing financial interests. pain conditions, there is accumulating evidence, predominantly in adults, that this disorder affects brain structure and function (Martucci and Mackey, 2016; Weaver et al., 2016). Recurring pain associated with other symptoms 
(e.g., alterations in bowel habits, affect) is present in IBS and may precede or drive the observed brain changes. In children, these changes may have both early and longterm effects on behavior and disease comorbidity (viz., long-term vulnerability to psychiatric illness including anxiety, depression, and somatoform disorders; Chitkara et al., 2008; Bradford et al., 2012; Surdea-Blaga et al., 2012; Shelby et al., 2013).

The cingulate cortex is considered a key hub in the putative salience and central autonomic networks, subserving a myriad of functions related to pain processing and integration, including salience detection, self-referential, and empathetic responses to pain, motor control related to pain expression and aversion, as well as the regulation of homeostatic and viscerosensory functions (Vogt et al., 1996; Bonaz, 2003; Rapps et al., 2008; Elsenbruch, 2011; Weaver et al., 2016). In adults with IBS, previous neuroimaging studies have demonstrated aberrant brain responses to actual or anticipated rectal distension in the cingulate cortex of these patients (Silverman et al., 1997; Mertz et al., 2000; Naliboff et al., 2001; Ringel et al., 2003; Verne et al., 2003; Kwan et al., 2005; Berman et al., 2008; Elsenbruch et al., 2010; Hall et al., 2010; Tillisch et al., 2011; Larsson et al., 2012). In addition, a number of studies using morphometric neuroimaging techniques have shown marked structural changes in cingulate gray and white matter (WM) architecture in adults with IBS compared to healthy individuals, including but not limited to alterations in cortical thickness, gray matter volume, and fractional anisotropy (FA; Davis et al., 2008; Taylor et al., 2009; Blankstein et al., 2010; Seminowicz et al., 2010; Chen et al., 2011; Ellingson et al., 2013; Piché et al., 2013; Hong et al., 2014). However, few studies have evaluated changes in brain structure and function in children with IBS (Huang et al., 2016; Hubbard et al., 2016; Liu et al., 2016), and no study to date has investigated differences in WM morphology in a pediatric population.

While adult studies confirm the nature of how IBS may affect the brain, evaluation of pediatric patients may confer insights into the magnitude of early life onset brain changes (related to disease duration), commonality of these changes when compared with adults and those regions of the brain that may be more or less affected during the childhood years. Here, we evaluate WM abnormalities using diffusion tensor imaging (DTI). Specifically, the aim of the current study was to examine WM changes, indexed by mean FA and other non-FA metrics [i.e., mean diffusivity (MD); radial diffusivity (RD)] in adolescents with IBS compared to healthy,

This work was supported by The Mayday/Louis Herlands Fund for Pain Research (D.B.), the National Institutes of Health Grant K24 DK082792 NIDDK (to S.N.), and the Behrakis Foundation (S.N.).

${ }^{*}$ D.B. and S.N. are joint senior authors and contributed equally to this work.

Acknowledgements: We thank our participants for their contributions to this study.

Correspondence should be addressed to Catherine S. Hubbard, Ph.D., Martinos Center for Biomedical Imaging, 149 13th Street, Room 2301, Charlestown, MA 02129, E-mail: catherine.hubbard@mgh.harvard.edu.

DOI:http://dx.doi.org/10.1523/ENEURO.0354-17.2018

Copyright (C) 2018 Hubbard et al.

This is an open-access article distributed under the terms of the Creative Commons Attribution 4.0 International license, which permits unrestricted use, distribution and reproduction in any medium provided that the original work is properly attributed. age- and gender-matched controls using whole-brain, region of interest (ROI)-restricted tract-based spatial statistics (TBSS) and canonical ROI-based DTI analyses for the cingulum bundle. We chose the cingulum bundle for our ROI analyses given its key role in processing the affectivemotivational and cognitive-evaluative components of pain, integration of homeostatic-viscerosensory and motor functions, as well as recent findings demonstrating aberrant functional connectivity patterns between this region and intrinsic brain networks during liminal and subliminal rectal distension in pediatric IBS subjects (Derbyshire, 2003; Liu et al., 2016; Weaver et al., 2016). We hypothesized that specific WM abnormalities localized to the cingulum bundle would be evident in adolescents with IBS. It was also predicted that early changes in diffusion derived metrics for the cingulum bundle would be related to symptom severity measures such as disease duration and pain intensity. Lastly, our rationale for conducting $\mathrm{ROI}$ analyses using two different approaches was based on studies reporting high variability in DTI parameters extracted from small structures and the possibility of including voxels impacted by partial volume effects (Ozturk et al., 2008; Hakulinen et al., 2012; Lilja et al., 2016). Given the ease of which TBSS can be performed, combined with an improved ability to detect small changes in FA between groups in an unbiased manner (Smith et al., 2006), and a previous report indicating high test-retest reliability and low variability (Lilja et al., 2016), we use this as our primary method and compare these results with the canonical ROI-based DTI approach.

\section{Materials and Methods}

\section{Participants}

Nineteen adolescents [16.00 \pm 2.09 years (mean \pm SD); females $=15$ ] with a diagnosis of IBS were prospectively recruited and enrolled in the current study. Human subjects were recruited from the Motility and Functional Gastrointestinal Disorders Center and the General Gl Clinics at Boston Children's Hospital. Patients were frequency matched for age and gender to a sample of 19 healthy controls taken from our existing imaging database. General inclusion criteria required that all participants were right-handed, between the ages of 8 and 21 years, had no indication of claustrophobia or suicidal ideation, passed MRI safety screening, tested negative for drugs of abuse in their urine, and for females, were not pregnant or planning to become pregnant. Scanning parameters for patient and control groups were identical and conducted using the same scanner. This study was conducted in accordance with the Declaration of Helsinki and approved by the Boston Children's Hospital Institutional Review Board. All participants provided written informed consent or verbal assent (with parental permission for children $<18$ years).

For IBS patients, diagnosis was made by a gastroenterologist using pediatric Rome III criteria (Drossman et al., 2006; Rasquin et al., 2006). Exclusion criteria for the patient group included any evidence of organic gastrointestinal (Gl) disease or hepatic disorders, or a serious CNS medical condition. Proton pump inhibitors and antispasmodics were allowed for patients on a stable dose for at 
least a four-week period before study inclusion. Patients on a stable (more than or equal to three months), low to moderate dose of a psychotropic medications such as anti-depressants or anxiolytics were also included.

\section{Clinical and psychometric measures}

Primary clinical severity measures included disease duration (duration of IBS symptoms in years) and pain intensity in regard to abdominal symptoms (over the past week; $0=$ no pain and $10=$ worst pain imaginable). The gastroenterologist assessed these measures verbally at the initial clinical visit. Before scanning patients completed a series of questionnaires including the abdominal pain index (API; Walker et al., 1997; Laird et al., 2015), the pediatric quality of life inventory (PedsQL; version 4.0; child report, ages 8-12; teen report, ages 13-18; young adult report, ages 18-25; Varni et al., 2001), the PedsQL Gl symptoms module (PedsQL GI module; version 3.0; Varni et al., 2014), and the functional disability inventory (FDI; Walker and Greene, 1991). Other self-report measures included the revised children's anxiety and depression scale (RCADS; Chorpita et al., 2000), and the pain catastrophizing scale-child version (PCS-C; Crombez et al., 2003).

\section{FA}

DTI is a MRI technique that exploits the inherent property of water molecules to diffuse in an anisotropic manner along neuronal fiber tracts, allowing for noninvasive visualization of microstructural changes in the human brain in vivo (Le Bihan et al., 2001; Soares et al., 2016). This technique permits both qualitative and quantitative measurement of the magnitude, directionality and overall structural integrity of WM, using DTI-derived metrics such as FA, MD, and RD (Basser, 1995; Pierpaoli et al., 1996). FA is thought to be a global measure of WM integrity, and may reflect nonspecific changes in WM due to various pathologic processes. In contrast, MD measures the rate of diffusion within a given voxel and is related to the amount of water contained within extracellular space, therefore it is inversely related to membrane density, whereas RD may be an indicator of demyelination/dysmyelination (Alexander et al., 2007; O'Donnell and Westin, 2011).

\section{MRI data acquisition}

Diffusion-weighted images (DWls) were acquired using a Siemens 3-T TrioTim Syngo MRI scanner (Siemens Medical Solutions) with a 32-channel head coil. A simultaneous multi-slice generalized autocalibrating partially parallel acquisition (GRAPPA; Griswold et al., 2002; Skare et al., 2007) echo planar imaging sequence (70 axial slices, FOV $=220 \mathrm{~mm}^{2}$, matrix $=110 \times 110$, slice thickness $=2 \mathrm{~mm}$, resolution $=2 \mathrm{~mm}^{3}$ isotropic, TR $=4600$ $\mathrm{ms}, \mathrm{TE}=89 \mathrm{~ms})$ with 64 direction diffusion gradients $(b=$ $1000 \mathrm{~s} / \mathrm{mm}^{2}$ ) was acquired with a GRAPPA acceleration factor of $R=2$ and a single nondiffusion weighted volume $\left(b_{0}=0 \mathrm{~s} / \mathrm{mm}^{2}\right)$.

\section{DTI preprocessing pipeline}

DWls were converted from dicom to nifti format using MRIConvert (version 2.0.8; https://lcni.uoregon.edu/ downloads/mriconvert) and preprocessed using the functional magnetic resonance imaging of the brain (FMRIB) software library (FSL), version 5.0.6. DWI images were visually inspected and corrected for image distortions and motion artifacts using FSL's (FSL 5.0.6; http://fsl.fmrib.ox.ac.uk/fsl/fslwiki/) eddy current correction. Individual brain masks were created with FSL's brain extraction tool (BET) and the FMRIB diffusion toolbox (FDT; version 3.0) was used to fit a diffusion tensor model to the data for each voxel using DTIfit. FA values were calculated and fed into the voxelwise whole-brain and ROI-restricted TBSS analysis described below, followed by a canonical ROI-based DTI analysis (Smith et al., 2006, 2007).

\section{Statistical analysis for demographic, clinical, and psychometric measures}

All statistical analyses for demographic, clinical and psychometric measures were performed in SPSS version 25. To examine whether groups differed in age, a univariate ANOVA was performed. A $\chi^{2}$ test of independence was also conducted to examine whether groups differed proportionally for the sex variable. Differences in both age and gender were not expected since groups were frequency matched on both variables. In addition, Pearson correlation coefficients were computed to investigate the relationship between the clinical and psychometric measures in the patient group. In the case where assumption of normality was not met, as determined by the ShapiroWilk test, scores were transformed using the natural logarithm. The resulting log-transformed scores were then used in the correlation analysis (two-tailed; $p<0.001$ deemed significant following Bonferroni adjustment for multiple comparisons). To visualize the relationship between clinical and psychometric variables, a heat map was generated with the correlation coefficients using $R$ statistical software program (version 3.3.3).

\section{Whole-brain, ROI-restricted TBSS and canonical ROI-based DTI analyses}

A series of standard voxelwise analyses for whole-brain and ROI-restricted TBSS were performed in FSL (Smith et al., 2006, 2007). The FMRIB58 FA $1 \mathrm{~mm}$ standard space template image was used as the registration target for each subject's FA image. Subjects' FA images were aligned into standard $1 \times 1 \times 1 \mathrm{~mm}$ MNI152 space using the nonlinear registration tool FNIRT, merged into a single 4D image, and the mean FA volume was calculated and thinned to generate the mean FA skeleton. The mean FA skeleton was thresholded at 0.2. Individual subjects aligned FA images were projected onto this skeleton and the resulting skeletonized FA data were fed into the voxelwise nonparametric permutation test. MD and RD maps were created by applying the same transformation matrices used to obtain the FA maps.

Whole-brain and ROI-restricted TBSS analyses were performed to investigate group differences in FA using randomise, a nonparametric permutation-based inference tool for thresholding statistical maps (Winkler et al., 2014). 


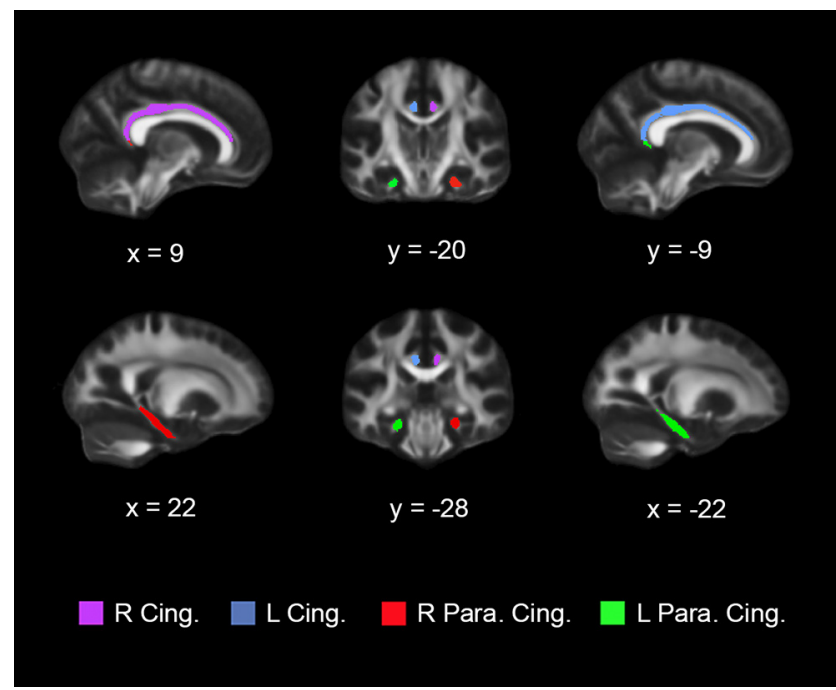

Figure 1. JHU WM tract masks used for the ROI-restricted TBSS and canonical ROI-based DTI analyses. Each ROI is color coded and overlaid onto a FMRIB58 FA $1 \mathrm{~mm}$ brain template. $\mathrm{R}$ Cing. = right cingulum; $\mathrm{L}$ Cing. = left cingulum; $\mathrm{R}$ Para. Cing. = right parahippocampal cingulum; L Para. Cing. = left parahippocampal cingulum.

The number of permutations was set to 10,000 and the threshold-free cluster enhancement (TFCE) option to correct for multiple comparisons were chosen (Smith and Nichols, 2009). For the ROI-restricted TBSS analysis, the mask option was also specified. Masks used for the ROIrestricted TBSS analyses were created by multiplying the mean FA skeleton mask, which was binarized and thresholded at 0.95 (i.e., $p=0.05$ ), with each of the four ROls (Fig. 1) using fslmaths. This resulted in the following four masks: right cingulum mask (voxels $=425$ ), left cingulum mask (voxels $=469$ ), right parahippocampal cingulum mask (voxels $=421$ ), and left parahippocampal cingulum mask (voxels $=442$ ). ROls for the cingulum were obtained directly from the ICBM-DTI-81 $1 \mathrm{~mm}$ FA atlas (Mori et al., 2008) of the Johns Hopkins University (JHU) DTI-based white-matter tractography atlas in FSL and consisted of the right and left subgenual and retrosplenial subdivisions combined, collectively referred to as the dorsal cingulum bundle, and a second pair of ROls, containing the right and left ventral aspect of the cingulum, referred to here as the parahippocampal cingulum bundle (Fig. 1).

Voxelwise statistics on skeletonized FA and non-FA data (MD and RD) were conducted between groups using a series of two-sample t-tests with age and gender specified as covariates of no interest and the mask option flagged with each of the four aforementioned masks (i.e., right and left cingulum and parahippocampal cingulum masks) using randomise. The resulting significant TFCEcorrected $p$ value statistical maps were thresholded at 0.95 (i.e., $p=0.05$ ) and binarized to create masks used for extraction of mean FA values from significant clusters using fslmeants command with the $4 \mathrm{D}$ skeletonized FA image specified as the input. In addition, mean MD and $R D$ values were extracted using the significant FA cluster mask and the 4D skeletonized MD or RD image specified as the input. Extracted mean $F A, M D$, and $R D$ values from significant cluster masks were then imported to SPSS (version 25) and bar graphs were created to visualize differences in group means.

For the canonical ROI-based DTI analysis a semiautomated ROI definition and deprojection method was used in FSL. All subjects' native T1 images were registered to the MNI T1 $1 \mathrm{~mm}$ brain template. Next, each subject's native FA image was nonlinearly registered to the MNI FMRIB58 FA $1 \mathrm{~mm}$ template using the fsl_reg command. Inverse nonlinear registration transformation parameters were generated and each of the four ROIs taken from the JHU ICBM-DTI-81 $1 \mathrm{~mm}$ FA atlas (R and L dorsal cingulum and parahippocampal cingulum ROls; Fig. 1) were deprojected using the invwarp command. Once each ROI was deprojected onto each subject's native FA map, fslmaths was used to extract mean FA values. The same procedure was followed to obtain mean $M D$ and $R D$ values. Extracted mean $F A, M D$ and $R D$ values from the four ROls for each subject were imported to SPSS for further analysis using a series of univariate ANOVAs with age and sex specified as covariates of no interest.

\section{Correlations between DTI metrics, clinical, and psychometric measures}

Linear regression was performed in SPSS to examine the relationship between mean $F A, M D$, and $R D$ values extracted from significant clusters and clinical measures of disease severity (i.e., disease duration and pain intensity) while controlling for age. Given the expected direction for the linear relationship between FA and disease severity measures, one-tailed tests were used for these analyses. In addition, regression analyses controlling for age were also conducted between mean FA, MD, and RD values extracted from significant clusters and scores from the psychometric measures. However, no a priori hypotheses were made regarding the expected direction; therefore, two-tailed tests were used. All $p$ values were corrected for multiple comparisons using Bonferroni adjustment.

\section{Results}

\section{Demographic, clinical, and psychometric measures}

Of the 19 adolescents with IBS enrolled, three were excluded from all statistical analyses; one patient was excluded due to being asymptomatic at the time of scanning, while two other patients were excluded due to either missing DWI data or venetian blind-like distortions, likely a result of excessive motion. After excluding these patients, our final patient sample consisted of 16 adolescents with a Rome III diagnosis of IBS (females $=12$; mean age \pm $\mathrm{SD}=16.29 \pm 1.78$, age range: $11.96-18.5$ years). These patients were frequency matched to 16 healthy participants (females $=12$; mean age $\pm S D=16.24 \pm 1.89$; age range: 11.71-20.32 years) on age and sex variables. Table 1 summarizes patient characteristics, and Table 2 displays descriptive statistics for clinical and psychometric measures for the patient group. With regard to bowel 
Table 1. Patient characteristics

\begin{tabular}{|c|c|c|c|c|c|c|c|c|c|c|c|c|c|c|c|}
\hline & $\begin{array}{c}\text { Age } \\
\text { (years) }\end{array}$ & Sex & $\begin{array}{l}\text { Bowel } \\
\text { habit }\end{array}$ & $\begin{array}{c}\text { Current } \\
\text { medications }\end{array}$ & $\begin{array}{l}\text { Comorbid } \\
\text { conditions }\end{array}$ & $\begin{array}{l}\text { Disease } \\
\text { duration }\end{array}$ & $\begin{array}{l}\text { Pain } \\
\text { intensity }\end{array}$ & API & FDI & PedsQL & $\begin{array}{c}\text { Gl } \\
\text { PedsQL }\end{array}$ & $\begin{array}{l}\text { T. anxiety } \\
\text { scr }\end{array}$ & $\begin{array}{l}\text { T. anxiety } \\
\text { depress. scr }\end{array}$ & $\begin{array}{l}\text { Depress. } \\
\text { scr }\end{array}$ & PSC-C \\
\hline$\overline{1}$ & 16.43 & $\mathrm{~F}$ & IBS-C & $\begin{array}{l}\text { Antiemetic, antispasmodic, } \\
\text { laxative, PPI }\end{array}$ & - & 3.0 & 2.08 & 2.45 & 7 & - & - & 16 & 23 & 48 & - \\
\hline 2 & 16.90 & $\mathrm{~F}$ & IBS-D & None & ACNES & 1.5 & 1.95 & 1.78 & 15 & - & - & - & - & - & - \\
\hline 3 & 13.28 & $\mathrm{~F}$ & IBS-C & Antiemetic, PPI & - & 2.0 & 1.95 & 2.15 & 30 & 51.09 & 48.31 & 24 & 37 & 63 & 3.22 \\
\hline 4 & 17.59 & $M$ & IBS-D & $\begin{array}{l}\text { Antiemetic, antihistamine, } \\
\text { antispasmodic, stool } \\
\text { softener }\end{array}$ & - & 5.0 & 1.95 & 1.78 & 22 & 76.09 & 68.24 & 9 & 15 & 47 & 2.77 \\
\hline 5 & 17.07 & $M$ & IBS-D & Antacid, antiemetic & - & 3.5 & 2.20 & 2.48 & 38 & 36.96 & 53.38 & 42 & 50 & 52 & 3.74 \\
\hline 6 & 17.55 & $\mathrm{~F}$ & IBS-C & GCC agonist, PPI & - & 1.0 & 1.95 & 3.30 & 14 & 60.87 & 50.68 & 21 & 39 & 66 & - \\
\hline 7 & 16.46 & $\mathrm{~F}$ & IBS-C & Antidepressant (SSRI) & ACNES & 2.0 & 2.08 & 3.30 & 14 & 63.04 & 46.28 & 31 & 43 & 56 & 3.56 \\
\hline 8 & 18.50 & $\mathrm{~F}$ & IBS-U & $\begin{array}{l}\text { Antacid, antihistamine, } \beta \text {-blocker, } \\
\text { NSAID, opioid analgesic } \\
\text { (meperidine), sedative } \\
\text { (ambien), TCA }\end{array}$ & - & 2.0 & 2.08 & 3.80 & 30 & 50.00 & 54.0 & 36 & 52 & 71 & 3.74 \\
\hline 9 & 15.86 & $\mathrm{~F}$ & IBS-C & $\begin{array}{l}\text { Antihistamine, NSAID, } \\
\text { PPI, antidepressant (TCA), } \\
\text { levothyroxine (TH) }\end{array}$ & $\begin{array}{l}\text { Ehlers-Danlos, } \\
\text { arthritis }\end{array}$ & 6.0 & 2.08 & 3.28 & 43 & 35.86 & 38.17 & 60 & 82 & 81 & 3.09 \\
\hline 10 & 18.30 & $\mathrm{~F}$ & IBS-C & $\begin{array}{l}\text { GCC agonist, PPI, } \\
\text { muscle relaxant, } \\
\text { anti-inflammatory }\end{array}$ & - & 6.0 & 2.30 & 3.00 & 10 & 64.13 & 37.16 & 15 & 23 & 47 & 2.64 \\
\hline 11 & 16.67 & $\mathrm{~F}$ & IBS-M & $\begin{array}{l}\text { Anti-inflammatory, } \beta \text {-blocker, } \\
\text { PPI, SRA (triptan), TCA }\end{array}$ & $\begin{array}{l}\text { Possible POTS, } \\
\text { occasional } \\
\text { migraine }\end{array}$ & 5.0 & 2.08 & 2.53 & 30 & 63.04 & 57.77 & 7 & 18 & 54 & 2.89 \\
\hline 12 & 16.87 & M & IBS-D & Antihistamine, PPI & - & 3.0 & 2.20 & 2.60 & 10 & 80.43 & 75.34 & 12 & 22 & 57 & 2.89 \\
\hline 13 & 15.06 & $\mathrm{~F}$ & IBS-M & $\begin{array}{l}\text { Antispasmodic, } \\
\text { laxative }\end{array}$ & - & 1.0 & 2.20 & 2.88 & 21 & - & - & 8 & 11 & 35 & - \\
\hline 14 & 14.65 & $\mathrm{~F}$ & IBS-C & $\begin{array}{l}\text { Antidepressant (SNRI), } \\
\text { laxative }\end{array}$ & - & 7.0 & 2.20 & 3.80 & 12 & 60.87 & 62.50 & 25 & 39 & 67 & 3.22 \\
\hline 15 & 11.96 & $\mathrm{~F}$ & IBS-C & $\begin{array}{l}\text { Inhaled, corticosteroid, } \\
\text { laxative, PPI, stool } \\
\text { softener, TCA }\end{array}$ & - & 8.0 & 2.08 & 1.65 & 24 & 52.17 & 64.58 & 24 & 32 & 8 & 3.43 \\
\hline 16 & 17.50 & $M$ & IBS-C & $\begin{array}{l}\text { Antihistamine, } \\
\text { laxative, PPI }\end{array}$ & $\begin{array}{l}\text { Barrett's } \\
\text { esophagus }\end{array}$ & 10.0 & 2.08 & 1.35 & 21 & 81.51 & 60.47 & 23 & 30 & 49 & 2.77 \\
\hline
\end{tabular}

ACNES = anterior cutaneous nerve entrapment syndrome; GCC = guanylate cyclase C agonist; NSAID = non-steroidal anti-inflammatory drug; SNRI = selective norepinephrine reuptake inhibitor; SSRI = selective-serotonin reuptake inhibitor; SRA = serotonin receptor agonist; TCA = tricyclic antidepressant; TH = thyroid hormone; PPI = proton-pump inhibitor; POTS = postural orthostatic tachycardia syndrome; API = abdominal pain index; FDI = functional; disability inventory; PedsQL = pediatric quality of life inventory; PedsQL GI = pediatric quality of life inventory gastrointestinal symptoms module; T. anxiety scr = total anxiety score; T. anxiety depress. scr = total anxiety depression score; Depress. scr = Depression score; PCS-C pain catastrophizing scale- child version.

habit subtype, the majority of patients reported constipation predominant symptoms (IBS with constipation, IBS-C $=9$, IBS with diarrhea, IBS-D = 4, mixed IBS, IBS-M = 2, unspecified IBS = 1; Table 1).

A one-way ANOVA reveled no significant group differences for age $\left[F_{(1,31)}=0.005, p=0.94\right]$. The $\chi^{2}$ test

Table 2. Descriptive statistics for clinical and psychometric measures

\begin{tabular}{lrrr}
\hline & \multicolumn{2}{c}{ IBS patients } & \\
\cline { 2 - 3 } & Mean & SD & $n$ \\
\hline Disease duration (years) & 4.125 & 2.699 & 16 \\
Pain intensity & 8.125 & 0.885 & 16 \\
API & 2.633 & 0.757 & 16 \\
FDI & 21.313 & 10.575 & 16 \\
PedsQL (total score) & 59.698 & 14.517 & 13 \\
GI PedsQL (total score) & 55.148 & 11.250 & 13 \\
RCADS - total anxiety score & 23.533 & 14.342 & 15 \\
RCADS - total anxiety depression score & 34.400 & 18.074 & 15 \\
RCADS - depression score & 53.400 & 17.029 & 15 \\
PCS-C & 25.333 & 10.012 & 12
\end{tabular}

$n$ = sample size; API = abdominal pain index; FDI = functional; disability inventory; PedsQL = pediatric quality of life inventory; PedsQL GI = pediatric quality of life inventory gastrointestinal symptoms module; $\mathrm{PCS}-\mathrm{C}=$ pain catastrophizing scale - child version; RCADS = revised children's anxiety and depression scale; SD = standard deviation.
(Fisher's exact test) also showed no difference in the proportion of males to females between healthy control and IBS groups $\left[\chi^{2}(1)=0, p=1.0\right]$. Shapiro-Wilk tests demonstrated that all variables met the assumption of normality with the exception of pain intensity, which was log-transformed, and these values were then used in all subsequent analyses.

\section{Whole-brain, ROI-restricted TBSS, and ROI-based DTI analyses}

Whole-brain TBSS analysis revealed no significant group differences in mean FA or non-FA metrics (MD or $\mathrm{RD}$ ) for adolescents with IBS versus controls following TFCE correction. In addition, we performed separate ROIrestricted TBSS analyses to examine WM FA differences for the right and left dorsal and parahippocampal cingulum in IBS patients versus controls. Results revealed a significant group difference in mean $\mathrm{FA}$ for the right dorsal cingulum ( $p<0.05$, TFCE corrected), but not for the left dorsal cingulum or the right or left parahpippocampal cingulum. Specifically, adolescents with IBS displayed lower FA (Fig. 2) for fiber tracts in the right dorsal cingulum compared to controls. ROI-restricted TBSS analyses performed using the right or left parahippocampal cingulum ROIs yielded no significant group differences for MD or 
A
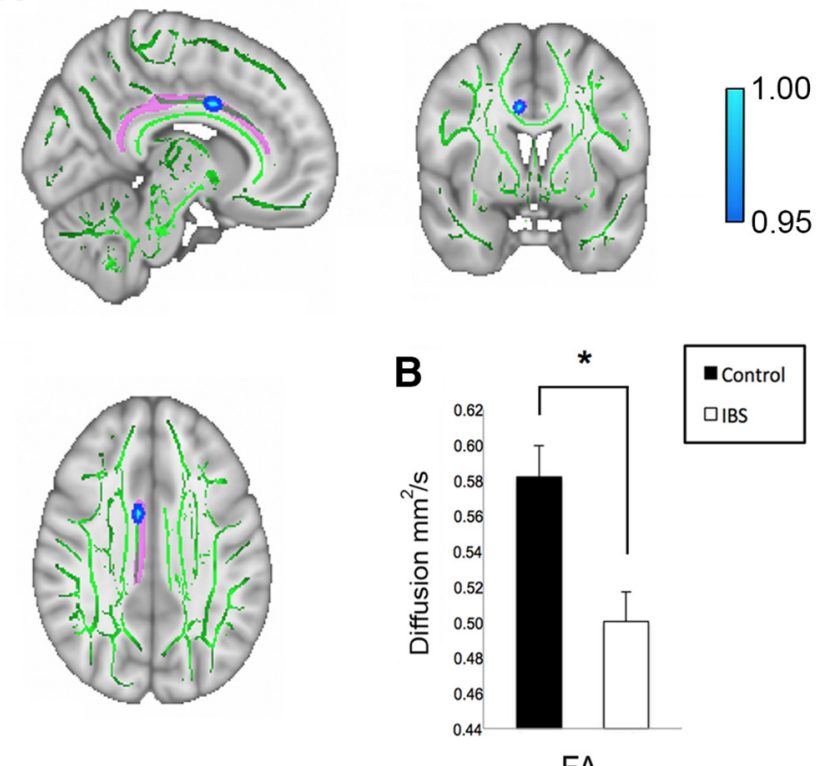

FA

Figure 2. Results from the ROI-restricted TBSS group analysis for the right dorsal cingulum. A, ROI-restricted TBSS analysis revealed a significant decrease in FA in adolescents with IBS compared to non-IBS cohort (IBS patients $<$ healthy controls; $p$ $<0.05$, TFCE corrected; color bar is scaled from 0.95 to 1 ) for a cluster located in the right dorsal cingulum. TFCE-corrected map overlaid onto $\mathrm{MNI} 152 \mathrm{~T} 1$ 1-mm brain and thresholded (0.2) mean FA skeleton (green) template in FSLView (version 3.2.0) with superimposed JHU binary mask for the right dorsal cingulum shown in pink. To improve visualization, FSL's tbss-fill command was used to thicken tracts that showed significant group differences in FA. MNI coordinates for the peak voxel in the FA cluster are $x=8.83, y=3.5, z=33.6$. Images are displayed in radiologic orientation. $\boldsymbol{B}$, Bar graph showing mean values extracted from significant FA cluster in IBS patients and healthy controls, $F_{(1,28)}=12.22, p=0.002$. Asterisk denotes significant group differences with IBS patients showing decreased FA compared to healthy controls.
RD following TFCE-correction. Consistent with results obtained for the ROI-restricted TBSS analysis, the ROIbased DTI analysis showed group differences in mean FA for the right dorsal cingulum bundle $\left(F_{(1,32)}=5.35, p=\right.$ 0.028 ) with IBS patients exhibiting statistically significant decreased mean FA compared to healthy controls (Fig. 3); No group differences for mean $\mathrm{MD}\left(F_{(1,32)}=0.92, p=\right.$ $0.514)$ or $\mathrm{RD}\left(F_{(1,32)}=4.25, p=0.287\right)$ for this $\mathrm{ROI}$, or extracted mean DTI metrics from the other ROls were found (Table 3).

To determine whether mean values for DTI metrics (FA, $M D$, and $R D$ ) extracted from the right dorsal cingulum differed within group using the two ROI methods (skeleton and canonical ROI analysis), a series of pairwise comparisons were conducted using paired sample t-tests, corrected for multiple comparisons with Bonferroni adjustments. Results showed that for the IBS group, mean FA $\left[t_{(15)}=7.24, p<\right.$ $0.0001], \mathrm{MD}\left[t_{(15)}=-5.01, p<0.0001\right]$, and $\mathrm{RD}\left[t_{(15)}=-6.71\right.$, $p<0.0001]$, differed significantly between methods. Similarly, mean FA $\left[t_{(15)}=10.59, p<0.0001\right], \mathrm{MD}\left[t_{(15)}=-5.16\right.$, $p<0.0001]$, and $\operatorname{RD}\left[t_{(15)}=-9.70, p<0.0001\right]$ also differed significantly between $\mathrm{ROI}$ analytical methods for the healthy control group.

\section{Correlations between disease severity, psychometric measures, and dorsal cingulum FA, MD, and RD in pediatric IBS}

For the patient group, regression analyses revealed no significant relationship between disease duration or pain intensity and mean FA (disease duration $R^{2}=0.012$; pain intensity $R^{2}=0.019$ ), MD (disease duration $R^{2}=0.055$; pain intensity $R^{2}=0.036$ ) or $\mathrm{RD}$ (disease duration $R^{2}=$ 0.038; pain intensity $R^{2}=0.009$ ) extracted from the significant FA cluster in the right dorsal cingulum from the ROI-restricted TBSS analysis. Individual regression analysis performed on mean $F A, M D$, and $R D$ values extracted from the TFCE-corrected significant cluster for the right dorsal cingulum and psychometric measures revealed no significant relationships following Bonferroni adjustment. Similarly, no significant relationships emerged from the
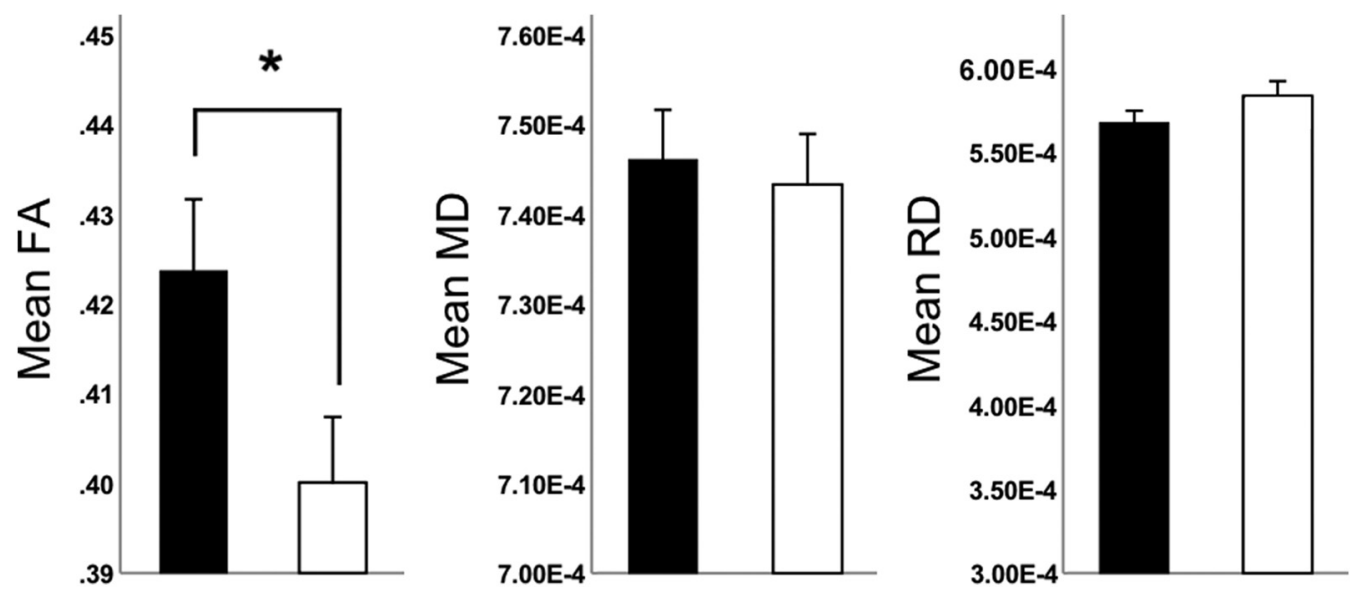

Figure 3. Results derived from the canonical ROI-based DTI analysis for the right dorsal cingulum. Bar graphs showing mean FA, MD, and RD values extracted from the right dorsal cingulum ROI in IBS patients (white bars) versus healthy controls (black bars). Asterisk denotes significant group differences with IBS patients showing decreased FA compared to healthy controls for the right dorsal cingulum $(p=0.028)$. 
Table 3. Descriptive statistics for mean FA, MD, and RD extracted from the right dorsal cingulum ROI for IBS and healthy control groups for the ROI-restricted TBSS and ROI-based DTI analyses

\begin{tabular}{|c|c|c|c|c|c|}
\hline \multirow[b]{2}{*}{ Method } & \multirow[b]{2}{*}{ DTI Metric } & \multicolumn{2}{|c|}{ IBS $(n=16)$} & \multicolumn{2}{|c|}{ Controls $(n=16)$} \\
\hline & & Mean & SD & Mean & SD \\
\hline ROI-restricted TBSS & FA & 0.500 & 0.067 & 0.582 & 0.070 \\
\hline & $\begin{array}{l}M D \\
\text { RD }\end{array}$ & $\begin{array}{l}6.90 \times 10^{-4} \\
4.85 \times 10^{-4}\end{array}$ & $\begin{array}{l}5.46 \times 10^{-5} \\
6.44 \times 10^{-5}\end{array}$ & $\begin{array}{l}6.90 \times 10^{-4} \\
4.35 \times 10^{-4}\end{array}$ & $\begin{array}{l}5.64 \times 10^{-5} \\
6.65 \times 10^{-5}\end{array}$ \\
\hline Canonical ROI-based DTI & $\begin{array}{l}\text { FA } \\
\text { MD } \\
\text { RD }\end{array}$ & $\begin{array}{l}0.400 \\
7.56 \times 10^{-4} \\
5.84 \times 10^{-4}\end{array}$ & $\begin{array}{l}0.029 \\
2.90 \times 10^{-5} \\
3.54 \times 10^{-5}\end{array}$ & $\begin{array}{l}0.424 \\
7.53 \times 10^{-4} \\
5.68 \times 10^{-4}\end{array}$ & $\begin{array}{l}0.032 \\
2.23 \times 10^{-5} \\
2.86 \times 10^{-5}\end{array}$ \\
\hline
\end{tabular}

$\mathrm{ROI}=$ region of interest; $\mathrm{FA}=$ fractional anisotropy; $\mathrm{MD}=$ mean diffusivity; $\mathrm{RD}=$ radial diffusivity; $n=$ sample size; $\mathrm{SD}=$ standard deviation .

regression analyses performed on extracted mean FA (disease duration $R^{2}=0.110$; pain intensity $R^{2}=0.067$ ), MD (disease duration $R^{2}=0.022$; pain intensity $R^{2}=$ 0.049 ), and $\mathrm{RD}$ (disease duration $R^{2}=0.013$; pain intensity $R^{2}=0.046$ ) using the standard ROI-based method for the right dorsal cingulum and disease severity measures (disease duration and pain intensity), or for the psychometric measures following Bonferroni correction.

\section{Correlations between clinical and psychometric variables}

Strength and direction of linear relationships between clinical variables and psychometric measures are dis- played in a heat map of correlation coefficients in Figure 4. No significant correlations were found between disease duration or pain intensity, or between these variables and any of the psychometric measures after Bonferroni adjustment. API scores positively correlated with depression scores on the RCADS $(r=0.62, p=0.02)$. FDI negatively correlated with PedsQL $(r=-0.73, p=0.005)$ and positively correlated with total anxiety $(r=0.62, p=0.01)$ and total anxiety depression $(r=0.59, p=0.02)$ RCADS scores. PedsQL positively correlated with GI PedsQL ( $r=$ $0.56, p=0.05)$ and negatively correlated with total anxiety $(r=-0.78, p=0.002)$ and total anxiety depression $(r=$ $-0.77, p=0.002)$ scores on the RCADS, and with pain

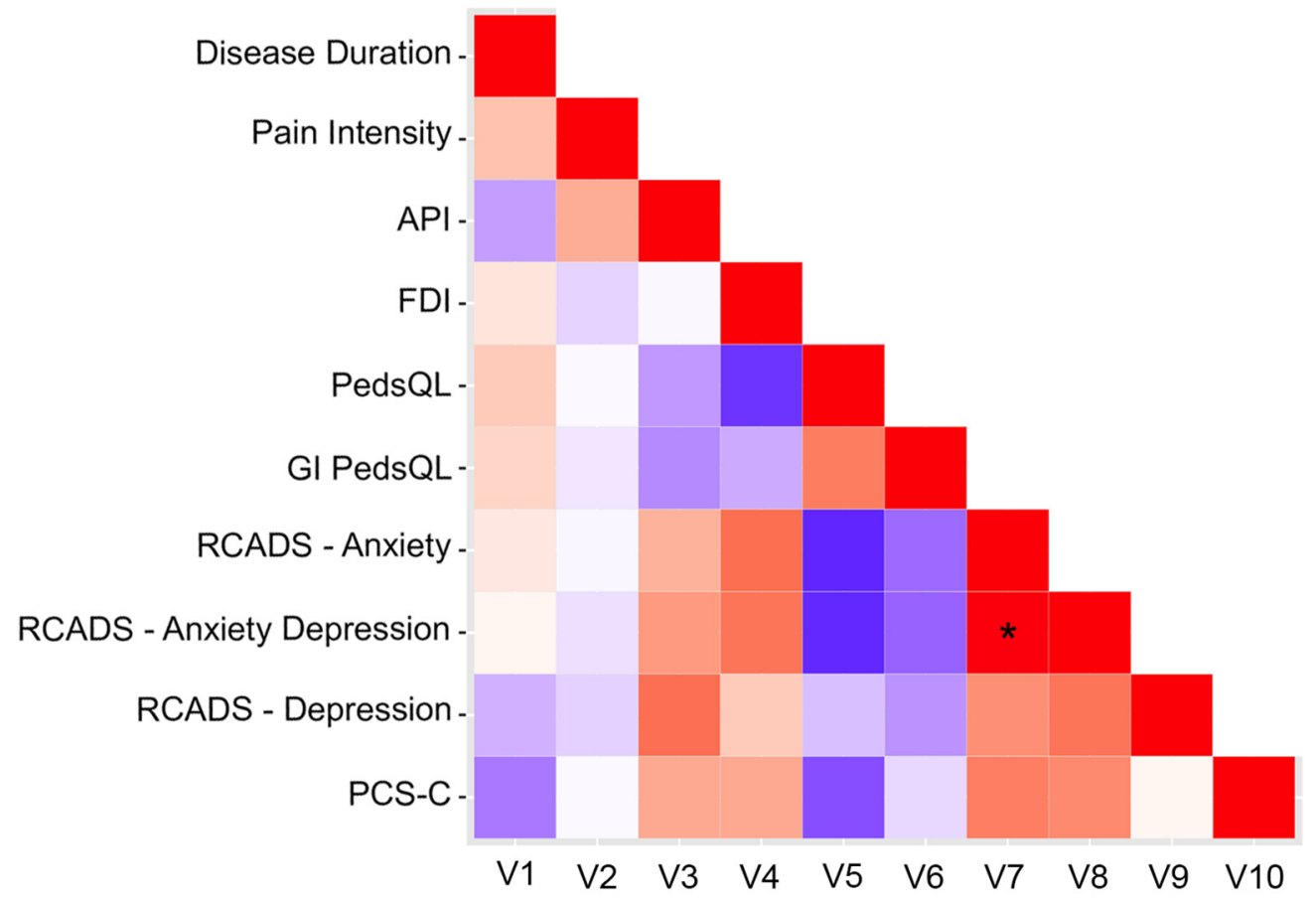

Pearson Correlation Coefficient $(r)$

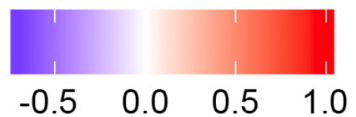

Figure 4. Heat map summarizing Pearson correlation coefficients $(r)$ for clinical and psychometric measures, uncorrected for multiple comparisons. Asterisk denotes correlation that remained significant after Bonferroni adjustment (adjusted $p$ value $=0.05 / 45=0.001$ ). 
catastrophizing scores from the PCS-C $(r=-0.63, p=$ $0.03)$. Total anxiety and total anxiety depression scores were positively correlated $(r=0.98, p<0.001)$, as was total anxiety depression scores with total depression $(r=$ $0.59, p=0.02$ ). It should be noted that the aforementioned results were not corrected for multiple comparisons. Using Bonferroni adjustment $(0.05 / 45=0.001)$, the only correlation that survived correction was between total anxiety and total anxiety depression scores $(r=0.98$, $p<0.0001$ ) from the RCADS.

\section{Discussion}

This study represents the first report of WM abnormalities specific to the cingulum bundle in adolescents with IBS. Our ROI-restricted TBSS analysis revealed a significant group difference in mean FA that survived TFCE correction in the right dorsal cingulum. Specifically, we found decreased FA in adolescent IBS patients relative to age- and gender-matched healthy controls in the medial portion of the right dorsal cingulum bundle (i.e., midcingulum). Moreover, the main finding of group differences in mean FA extracted from our ROl-based DTI analysis were consistent with findings from our ROIrestricted TBSS analysis; IBS patients showed significantly lower mean FA values for the right dorsal cingulum compared to healthy controls. These results indicate that the ROI-restricted TBSS approach may be valid in restricted search areas for well-defined tracts that can be identified reliably across subjects, such as in the case of the cingulum bundle (Lilja et al., 2016). However, contrary to our predictions, clinical measures of disease duration and pain intensity were unrelated to FA in IBS patients using both ROI-based methods. Longitudinal studies are needed in larger samples of pediatric IBS patients to determine whether the WM abnormalities observed here endure over time or instead represent some sort of malleable, microstructural reorganizational changes that manifest early in the course of the disease.

\section{Why the cingulum?}

The cingulum contains bundles of WM tracts that surround the corpus callosum, connecting the cingulate cortex with a number of limbic and paralimbic regions and cortical association areas in the frontal, temporal, and parietal lobes (Jones et al., 2013). Anatomically, it consists of many short fiber tracts that form interregional connections within the cingulum itself, and longer fiber tracts that link more distant regions together. Based on tract-tracing studies in nonhuman primates and recent tractography studies using DTI techniques in humans, the cingulum can be topographically organized into at least three subdivisions, a dorsal aspect containing the subgenual and retrosplenial subdivisions and a ventral aspect, containing the parahippocampal subdivision (Jones et al., 2013). The WM changes observed in this study were localized to an area within the retrosplenial portion of the cingulum bundle. It contains fibers that have reciprocal connections between the prefrontal cortex, anterior cingulate, and posterior cingulate cortices (Goldman-Rakic et al., 1984; Mufson and Pandya, 1984; Vogt and Pandya, 1987; Kobayashi and Amaral, 2003, 2007). In addition, there is a contribution of fiber connections from the thalamus (anterior and lateral dorsal nuclei; Mufson and Pandya, 1984). The anterior thalamus has a number of highly conserved subnuclei involved in learning and memory (Jankowski et al., 2013), which have been postulated to subserve an "extended hippocampal function" (Aggleton et al., 2010). The anterior thalamic inputs may be a conduit for the observed anatomical changes in this study. In addition to these diffuse fiber tracts that connect to thalamic regions involved in many of the maladaptive behavioral manifestations that accompany clinical presentation of IBS, there is data to support direct medial thalamic connections via the spinothalamic tract, a key pathway conveying nociceptive signals from visceral and somatic afferents (Ammons et al., 1985). Preclinical studies implicate the centromedial portion of the right and left cingulum bundle in nociception (Nikenina et al., 2008). Microinjections of lidocaine temporarily blocks formalin-induced nociceptive responses and electrical stimulation to the cingulum bundle and surrounding tissue has been shown to have analgesic effects (Vaccarino and Melzack, 1989, 1992; Fuchs et al., 1996). Moreover, the role of the cingulum in negative affective states and in the subjective experience of pain is well described. There is evidence that lesioning these fiber tracts in cases of intractable cancer pain or other chronic pain conditions results in diminished pain with patients reporting that they are less likely to be bothered by their pain (Yen et al., 2005; Sharim and Pouratian, 2016), suggesting that the cingulum may subserve evaluative functions related to the aversiveness of pain and not pain intensity per se. Extrapolating this, ongoing pain signaling via medial pain pathway may result in central sensitization of spinothalamic afferents, which over time could manifest in abnormalities further upstream, in WM tracts of the cingulum.

\section{WM brain changes in youth versus adults with IBS}

This is the first DTI analysis in adolescents with a diagnosis of IBS. The focal changes observed in this younger population are different from the more widespread changes seen in adult IBS patients, perhaps indicative of initial effects of the disease. For example, a few studies investigating DTI related changes in adults with IBS have reported WM alterations in a number of brain regions including insula, thalamus, basal ganglia, and somatosensory cortex (Chen et al., 2011; Ellingson et al., 2013). We interpret these focal changes as likely suggestive of early expression of the disease on WM tracts; however, this may or may not be the case. A more parsimonious explanation may be that these findings simply reflect variability of the adolescent brain combined with the small sample size. Clearly, longitudinal studies are needed with larger sample sizes to provide insight into the causal relationship between early brain changes and clinical manifestations of the disease state.

FA is said to be sensitive to subtle, nonspecific changes in WM architecture indicative of neuropathological processes, whereas MD and RD may be more sensitive measures of WM pathology that results from neuroinflammation, edema, hypoxia, necrosis, tissue cellular density (i.e., cellularity), demyelination, and changes in axonal 
diameter or density (Sugahara et al., 1999; Gauvain et al., 2001; Beaulieu, 2002; Mac Donald et al., 2007). Although our study findings point to decreased FA in the right dorsal cingulum in young IBS patients compared to matched healthy controls, the pathogenesis underlying these WM changes cannot be discerned from the present data. WM abnormalities in FA and other non-FA metrics in the cingulum have been linked to anxiety disorders such generalized anxiety disorder, obsessive-compulsive disorder and post-traumatic stress disorder (Lochner et al., 2012; Daniels et al., 2013; Wang et al., 2016), as well a various pain conditions, including complex regional pain syndrome (CRPS), temporomandibular disorder, chronic musculoskeletal pain, trigeminal neuralgia, and IBS (Geha et al., 2008; Chen et al., 2011; Moayedi et al., 2012; Ellingson et al., 2013; DeSouza et al., 2014; Lieberman et al., 2014; Qi et al., 2016). Therefore, it is possible that the observed microstructural WM changes reflect sensitization of viscerosomatic nociceptive afferents, leading to functional reorganization in spinothalamic and corticolimbic tracts involved in processing pain and affect, including the dorsal cingulum bundle.

\section{Limitations}

There are a number of limitations to this study: (1) Sample size: while pediatric studies are more challenging than adult studies, the small sample size and heterogeneity of bowel habit subtypes limit generalizability of our findings. (2) Medications: some of our patients were taking medications with CNS effects, including antidepressants and anxiolytics, and this may have impacted our results in an negative manner. Despite the degree of difficulty in recruiting adolescents with IBS to participate in a neuroimaging study, all effort was made to exclude patients on high doses of antidepressants or anxiolytics, and only patients on stable doses were enrolled. (3) Pubertal changes: another limitation of this study was that we did not control for pubertal changes which have been shown to be linked to brain maturation, including WM development, during childhood and adolescence (Blakemore et al., 2010; Herting and Sowell, 2017). However, we did control for age in our statistical analyses as well as age- and sex-matched subjects between groups, which should have minimized the impact of pubertal changes on our results, balancing these effects across groups. (4) Pre-existing brain state versus consequences of disease state: this is obviously difficult to know, but due to inherent genetic makeup of an individual actual manifestations of the disease state may follow these early brain changes, occurring before symptomatic disease onset. Conversely, the disease state itself may precipitate these brain changes.

\section{Conclusions}

Our findings in young patients with IBS showed significant alterations in WM integrity for fibers in the right dorsal cingulum bundle that were not related to disease duration or abdominal pain severity. These results provide a basis for understanding the longitudinal natural history of microstructural brain changes in those patients in which the disease persists and may give some insight into the pathophysiology of IBS.

\section{References}

Aggleton JP, O'Mara SM, Vann SD, Wright NF, Tsanov M, Erichsen JT (2010) Hippocampal-anterior thalamic pathways for memory: uncovering a network of direct and indirect actions. Eur J Neurosci 31:2292-2307. CrossRef

Alexander AL, Lee JE, Lazar M, Field AS (2007) Diffusion tensor imaging of the brain. Neurotherapeutics 4:316-329. CrossRef

Ammons WS, Girardot MN, Foreman RD (1985) T2-T5 spinothalamic neurons projecting to medial thalamus with viscerosomatic input. J Neurophysiol 54:73-89. CrossRef Medline

Basser PJ (1995) Inferring microstructural features and the physiological state of tissues from diffusion-weighted images. NMR Biomed 8:333-344. CrossRef

Beaulieu C (2002) The basis of anisotropic water diffusion in the nervous system - a technical review. NMR Biomed 15:435-455. CrossRef

Berman SM, Naliboff BD, Suyenobu B, Labus JS, Stains J, Ohning G, Kilpatrick L, Bueller JA, Ruby K, Jarcho J, Mayer EA (2008) Reduced brainstem inhibition during anticipated pelvic visceral pain correlates with enhanced brain response to the visceral stimulus in women with irritable bowel syndrome. J Neurosci 28:349-359. CrossRef

Blakemore SJ, Burnett S, Dahl RE (2010) The role of puberty in the developing adolescent brain. Hum Brain Mapp 31:926-933. CrossRef

Blankstein U, Chen J, Diamant NE, Davis KD (2010) Altered brain structure in irritable bowel syndrome: potential contributions of pre-existing and disease-driven factors. Gastroenterology 138: 1783-1789. CrossRef

Bonaz B (2003) Visceral sensitivity perturbation integration in the brain-gut axis in functional digestive disorders. J Physiol Pharmacol 54:27-42.

Bradford K, Shih W, Videlock EJ, Presson AP, Naliboff BD, Mayer EA, Chang $L$ (2012) Association between early adverse life events and irritable bowel syndrome. Clin Gastroenterol Hepatol 10:385390.e1-3. CrossRef

Chen JY, Blankstein U, Diamant NE, Davis KD (2011) White matter abnormalities in irritable bowel syndrome and relation to individual factors. Brain Res 1392:121-131. CrossRef

Chitkara DK, van Tilburg MA, Blois-Martin N, Whitehead WE (2008) Early life risk factors that contribute to irritable bowel syndrome in adults: a systematic review. Am J Gastroenterol 103:765-774; quiz 775. CrossRef

Chorpita BF, Yim L, Moffitt C, Umemoto LA, Francis SE (2000) Assessment of symptoms of DSM-IV anxiety and depression in children: a revised child anxiety and depression scale. Behav Res Ther 38:835-855. Medline

Crombez G, Bijttebier P, Eccleston C, Mascagni T, Mertens G, Goubert L, Verstraeten K (2003) The child version of the pain catastrophizing scale (PCS-C): a preliminary validation. Pain 104: 639-646. Medline

Daniels JK, Lamke JP, Gaebler M, Walter H, Scheel M (2013) White matter integrity and its relationship to PTSD and childhood trauma-a systematic review and meta-analysis. Depress Anxiety 30: 207-216. CrossRef

Davis KD, Pope G, Chen J, Kwan CL, Crawley AP, Diamant NE (2008) Cortical thinning in IBS: implications for homeostatic, attention, and pain processing. Neurology 70:153-154. CrossRef

Derbyshire SW (2003) A systematic review of neuroimaging data during visceral stimulation. Am J Gastroenterol 98:12-20. CrossRef

DeSouza DD, Hodaie M, Davis KD (2014) Abnormal trigeminal nerve microstructure and brain white matter in idiopathic trigeminal neuralgia. Pain 155:37-44. CrossRef

Drossman DA, Corazziari E, Delvaux M, Spiller R, Talley NJ, Thompson WG, Whitehead WE (2006) Rome III: the functional gastrtointestinal disorders (Ed 3). McLean, VA: Degnon Associates.

Ellingson BM, Mayer E, Harris RJ, Ashe-McNally C, Naliboff BD, Labus JS, Tillisch K (2013) Diffusion tensor imaging detects mi- 
crostructural reorganization in the brain associated with chronic irritable bowel syndrome. Pain 154:1528-1541. CrossRef

Elsenbruch S (2011) Abdominal pain in irritable bowel syndrome: a review of putative psychological, neural and neuro-immune mechanisms. Brain Behav Immun 25:386-394. CrossRef

Elsenbruch S, Rosenberger C, Bingel U, Forsting M, Schedlowski M, Gizewski ER (2010) Patients with irritable bowel syndrome have altered emotional modulation of neural responses to visceral stimuli. Gastroenterology 139:1310-1319. CrossRef

Fuchs PN, Balinsky M, Melzack R (1996) Electrical stimulation of the cingulum bundle and surrounding cortical tissue reduces formalintest pain in the rat. Brain Res 743:116-123.

Gauvain KM, McKinstry RC, Mukherjee P, Perry A, Neil JJ, Kaufman BA, Hayashi RJ (2001) Evaluating pediatric brain tumor cellularity with diffusion-tensor imaging. AJR Am J Roentgenol 177:449454. CrossRef

Geha PY, Baliki MN, Harden RN, Bauer WR, Parrish TB, Apkarian AV (2008) The brain in chronic CRPS pain: abnormal gray-white matter interactions in emotional and autonomic regions. Neuron 60: 570-581. CrossRef

Goldman-Rakic PS, Selemon LD, Schwartz ML (1984) Dual pathways connecting the dorsolateral prefrontal cortex with the hippocampal formation and parahippocampal cortex in the rhesus monkey. Neuroscience 12:719-743. CrossRef

Griswold MA, Jakob PM, Heidemann RM, Nittka M, Jellus V, Wang J, Kiefer B, Haase A (2002) Generalized autocalibrating partially parallel acquisitions (GRAPPA). Magn Reson Med 47:1202-1210. CrossRef

Hakulinen U, Brander A, Ryymin P, Öhman J, Soimakallio S, Helminen M, Dastidar P, Eskola H (2012) Repeatability and variation of region-of-interest methods using quantitative diffusion tensor MR imaging of the brain. BMC Med Imaging 12:30. CrossRef

Hall GB, Kamath MV, Collins S, Ganguli S, Spaziani R, Miranda KL, Bayati A, Bienenstock J (2010) Heightened central affective response to visceral sensations of pain and discomfort in IBS. Neurogastroenterol Motil 22:e276-e280. CrossRef

Herting MM, Sowell ER (2017) Puberty and structural brain development in humans. Front Neuroendocrinol 44:122-137. CrossRef

Hong JY, Labus JS, Jiang Z, Ashe-Mcnalley C, Dinov I, Gupta A, Shi Y, Stains J, Heendeniya N, Smith SR, Tillisch K, Mayer EA (2014) Regional neuroplastic brain changes in patients with chronic inflammatory and non-inflammatory visceral pain. PLoS One 9:e84564. CrossRef

Huang JS, Terrones L, Simmons AN, Kaye W, Strigo I (2016) Pilot study of functional magnetic resonance imaging responses to somatic pain stimuli in youth with functional and inflammatory gastrointestinal disease. J Pediatr Gastroenterol Nutr 63:500-507. CrossRef

Hubbard CS, Becerra L, Heinz N, Ludwick A, Rasooly T, Wu R, Johnson A, Schechter NL, Borsook D, Nurko S (2016) Abdominal pain, the adolescent and altered brain structure and function. PLoS One 11:e0156545. CrossRef

Jankowski MM, Ronnqvist KC, Tsanov M, Vann SD, Wright NF, Erichsen JT, Aggleton JP, O'Mara SM (2013) The anterior thalamus provides a subcortical circuit supporting memory and spatial navigation. Front Syst Neurosci 7:45. CrossRef

Jones DK, Christiansen KF, Chapman RJ, Aggleton JP (2013) Distinct subdivisions of the cingulum bundle revealed by diffusion MRI fibre tracking: implications for neuropsychological investigations. Neuropsychologia 51:67-78. CrossRef

Kobayashi Y, Amaral DG (2003) Macaque monkey retrosplenial cortex: II. Cortical afferents. J Comp Neur 466:48-79. CrossRef

Kobayashi Y, Amaral DG (2007) Macaque monkey retrosplenial cortex: III. Cortical efferents. J Comp Neur 502:810-833. CrossRef

Kwan CL, Diamant NE, Pope G, Mikula K, Mikulis DJ, Davis KD (2005) Abnormal forebrain activity in functional bowel disorder patients with chronic pain. Neurology 65:1268-1277. CrossRef

Laird KT, Sherman AL, Smith CA, Walker LS (2015) Validation of the abdominal pain index using a revised scoring method. J Pediatr Psychol 40:517-525. CrossRef
Larsson MB, Tillisch K, Craig AD, Engström M, Labus J, Naliboff B, Lundberg P, Ström M, Mayer EA, Walter SA (2012) Brain responses to visceral stimuli reflect visceral sensitivity thresholds in patients with irritable bowel syndrome. Gastroenterology 142:463472.e3. CrossRef

Le Bihan D, Mangin JF, Poupon C, Clark CA, Pappata S, Molko N, Chabriat H (2001) Diffusion tensor imaging: concepts and applications. J Magn Reson Imaging 13:534-546. Medline

Lieberman G, Shpaner M, Watts R, Andrews T, Filippi CG, Davis M, Naylor MR (2014) White matter involvement in chronic musculoskeletal pain. J Pain 15:1110-1119. CrossRef

Lilja Y, Gustafsson O, Ljungberg M, Nilsson D, Starck G (2016) Impact of region-of-interest method on quantitative analysis of DTI data in the optic tracts. BMC Med Imaging 16:42. CrossRef

Liu X, Silverman A, Kern M, Ward BD, Li SJ, Shaker R, Sood MR (2016) Excessive coupling of the salience network with intrinsic neurocognitive brain networks during rectal distension in adolescents with irritable bowel syndrome: a preliminary report. Neurogastroenterol Motil 28:43-53. CrossRef

Lochner C, Fouché JP, Du Plessis S, Spottiswoode B, Seedat S, Fineberg N, Chamberlain SR, Stein DJ (2012) Evidence for fractional anisotropy and mean diffusivity white matter abnormalities in the internal capsule and cingulum in patients with obsessivecompulsive disorder. J Psychiatry Neurosci 37:193-199. CrossRef

Longstreth GF, Thompson WG, Chey WD, Houghton LA, Mearin F, Spiller RC (2006) Functional bowel disorders. Gastroenterology 130:1480-1491. CrossRef

Mac Donald CL, Dikranian K, Bayly P, Holtzman D, Brody D (2007) Diffusion tensor imaging reliably detects experimental traumatic axonal injury and indicates approximate time of injury. J Neurosci 27:11869-11876. CrossRef

Martucci KT, Mackey SC (2016) Imaging pain. Anesthesiol Clin 34: 255-269. CrossRef

Mertz H, Morgan V, Tanner G, Pickens D, Price R, Shyr Y, Kessler R (2000) Regional cerebral activation in irritable bowel syndrome and control subjects with painful and nonpainful rectal distention. Gastroenterology 118:842-848. CrossRef

Moayedi M, Weissman-Fogel I, Salomons TV, Crawley AP, Goldberg MB, Freeman BV, Tenenbaum HC, Davis KD (2012) White matter brain and trigeminal nerve abnormalities in temporomandibular disorder. Pain 153:1467-1477. CrossRef

Mori S, Oishi K, Jiang H, Jiang L, Li X, Akhter K, Hua K, Faria AV, Mahmood A, Woods R, Toga AW, Pike GB, Neto PR, Evans A, Zhang J, Huang H, Miller Ml, van Zijl P, Mazziotta J (2008) Stereotaxic white matter atlas based on diffusion tensor imaging in an ICBM template. Neuroimage 40:570-582. CrossRef

Mufson EJ, Pandya DN (1984) Some observations on the course and composition of the cingulum bundle in the rhesus monkey. J Comp Neur 225:31-43. CrossRef

Naliboff BD, Derbyshire SW, Munakata J, Berman S, Mandelkern M, Chang L, Mayer EA (2001) Cerebral activation in patients with irritable bowel syndrome and control subjects during rectosigmoid stimulation. Psychosom Med 63:365-375. CrossRef

Nikenina EV, Abramov YB, Kozlov AY, Vasiltcova EV (2008) Role of caudomedial portion in left and right cingulum bundle in perceptual and emotional components of nociception in rats. Bull Exp Biol Med 145:165-167. Medline

O'Donnell LJ, Westin CF (2011) An introduction to diffusion tensor image analysis. Neurosurg Clin N Am 22:185-196, viii. CrossRef

Ozturk A, Sasson AD, Farrell JA, Landman BA, da Motta AC, Aralasmak A, Yousem DM (2008) Regional differences in diffusion tensor imaging measurements: assessment of intrarater and interrater variability. AJNR Am J Neuroradiol 29:1124-1127. CrossRef

Piché M, Chen Jl, Roy M, Poitras P, Bouin M, Rainville P (2013) Thicker posterior insula is associated with disease duration in women with irritable bowel syndrome (IBS) whereas thicker orbitofrontal cortex predicts reduced pain inhibition in both IBS patients and controls. J Pain 14:1217-1226. CrossRef 
Pierpaoli C, Jezzard P, Basser PJ, Barnett A, Di Chiro G (1996) Diffusion tensor MR imaging of the human brain. Radiology 201: 637-648. CrossRef

Qi R, Liu C, Weng Y, Xu Q, Chen L, Wang F, Zhang LJ, Lu GM (2016) Disturbed interhemispheric functional connectivity rather than structural connectivity in irritable bowel syndrome. Front Mol Neurosci 9:141. CrossRef

Rapps N, van Oudenhove L, Enck P, Aziz Q (2008) Brain imaging of visceral functions in healthy volunteers and IBS patients. J Psychosom Res 64:599-604. CrossRef

Rasquin A, Di Lorenzo C, Forbes D, Guiraldes E, Hyams JS, Staiano A, Walker LS (2006) Childhood functional gastrointestinal disorders: child/adolescent. Gastroenterology 130:1527-1537. CrossRef

Ringel Y, Drossman DA, Turkington TG, Bradshaw B, Hawk TC, Bangdiwala S, Coleman RE, Whitehead WE (2003) Regional brain activation in response to rectal distension in patients with irritable bowel syndrome and the effect of a history of abuse. Dig Dis Sci 48:1774-1781.

Seminowicz DA, Labus JS, Bueller JA, Tillisch K, Naliboff BD, Bushnell MC, Mayer EA (2010) Regional gray matter density changes in brains of patients with irritable bowel syndrome. Gastroenterology 139:48-57.e2. CrossRef

Sharim J, Pouratian N (2016) Anterior cingulotomy for the treatment of chronic intractable pain: a systematic review. Pain Physician 19:537-550. Medline

Shelby GD, Shirkey KC, Sherman AL, Beck JE, Haman K, Shears AR, Horst SN, Smith CA, Garber J, Walker LS (2013) Functional abdominal pain in childhood and long-term vulnerability to anxiety disorders. Pediatrics 132:475-482. CrossRef

Silverman DH, Munakata JA, Ennes H, Mandelkern MA, Hoh CK, Mayer EA (1997) Regional cerebral activity in normal and pathological perception of visceral pain. Gastroenterology 112:64-72. CrossRef

Skare S, Newbould RD, Clayton DB, Albers GW, Nagle S, Bammer R (2007) Clinical multishot DW-EPI through parallel imaging with considerations of susceptibility, motion, and noise. Magn Reson Med 57:881-890. CrossRef

Smith SM, Nichols TE (2009) Threshold-free cluster enhancement: addressing problems of smoothing, threshold dependence and localisation in cluster inference. Neuroimage 44:83-98. CrossRef

Smith SM, Jenkinson M, Johansen-Berg H, Rueckert D, Nichols TE, Mackay CE, Watkins KE, Ciccarelli O, Cader MZ, Matthews PM, Behrens TE (2006) Tract-based spatial statistics: voxelwise analysis of multi-subject diffusion data. Neuroimage 31:1487-1505. CrossRef

Smith SM, Johansen-Berg H, Jenkinson M, Rueckert D, Nichols TE, Miller KL, Robson MD, Jones DK, Klein JC, Bartsch AJ, Behrens TE (2007) Acquisition and voxelwise analysis of multi-subject diffusion data with tract-based spatial statistics. Nat Protoc 2:499503. CrossRef

Soares JM, Magalhães R, Moreira PS, Sousa A, Ganz E, Sampaio A, Alves V, Marques P, Sousa N (2016) A Hitchhiker's guide to functional magnetic resonance imaging. Front Neurosci 10:515. CrossRef

Sugahara T, Korogi Y, Kochi M, Ikushima I, Shigematu Y, Hirai T, Okuda T, Liang L, Ge Y, Komohara Y, Ushio Y, Takahashi M (1999)
Usefulness of diffusion-weighted MRI with echo-planar technique in the evaluation of cellularity in gliomas. J Magn Reson Imaging 9:53-60. Medline

Surdea-Blaga T, Băban A, Dumitrascu DL (2012) Psychosocial determinants of irritable bowel syndrome. World $\mathrm{J}$ Gastroenterol 18:616-626. CrossRef

Taylor KS, Seminowicz DA, Davis KD (2009) Two systems of resting state connectivity between the insula and cingulate cortex. Hum Brain Mapp 30:2731-2745. CrossRef

Tillisch K, Mayer EA, Labus JS (2011) Quantitative meta-analysis identifies brain regions activated during rectal distension in irritable bowel syndrome. Gastroenterology 140:91-100. CrossRef

Vaccarino AL, Melzack R (1989) Analgesia produced by injection of lidocaine into the anterior cingulum bundle of the rat. Pain 39:213219. Medline

Vaccarino AL, Melzack R (1992) Temporal processes of formalin pain: differential role of the cingulum bundle, fornix pathway and medial bulboreticular formation. Pain 49:257-271. CrossRef

Varni JW, Seid M, Kurtin PS (2001) PedsQL 4.0: reliability and validity of the pediatric quality of life inventory version 4.0 generic core scales in healthy and patient populations. Med Care 39:800-812. Medline

Varni JW, Bendo CB, Denham J, Shulman RJ, Self MM, Neigut DA, Nurko S, Patel AS, Franciosi JP, Saps M, Verga B, Smith A, Yeckes A, Heinz N, Langseder A, Saeed S, Zacur GM, Pohl JF (2014) PedsQL gastrointestinal symptoms module: feasibility, reliability, and validity. J Pediatr Gastroenterol Nutr 59:347-355. CrossRef

Verne GN, Himes NC, Robinson ME, Gopinath KS, Briggs RW, Crosson B, Price DD (2003) Central representation of visceral and cutaneous hypersensitivity in the irritable bowel syndrome. Pain 103:99-110. CrossRef

Vogt BA, Pandya DN (1987) Cingulate cortex of the rhesus monkey: II. Cortical afferents. J Comp Neur 262:271-289. CrossRef

Vogt BA, Derbyshire S, Jones AK (1996) Pain processing in four regions of human cingulate cortex localized with co-registered PET and MR imaging. Eur J Neurosci 8:1461-1473. Medline

Walker L, Smith CA, Garber J, Van Slyke DA (1997) Development and validation of the pain response inventory for children. Psychological Assessment 9:392-405. CrossRef

Walker LS, Greene JW (1991) The functional disability inventory: measuring a neglected dimension of child health status. $J$ Pediatr Psychol 16:39-58. CrossRef

Wang W, Qian S, Liu K, Li B, Li M, Xin K, Sun G (2016) Reduced white matter integrity and its correlation with clinical symptom in firstepisode, treatment-naive generalized anxiety disorder. Behav Brain Res 314:159-164. CrossRef

Weaver KR, Sherwin LB, Walitt B, Melkus GD, Henderson WA (2016) Neuroimaging the brain-gut axis in patients with irritable bowel syndrome. World J Gastrointest Pharmacol Ther 7:320-333. CrossRef

Winkler AM, Ridgway GR, Webster MA, Smith SM, Nichols TE (2014) Permutation inference for the general linear model. Neuroimage 92:381-397. CrossRef

Yen CP, Kung SS, Su YF, Lin WC, Howng SL, Kwan AL (2005) Stereotactic bilateral anterior cingulotomy for intractable pain. $\mathrm{J}$ Clin Neurosci 12:886-890. CrossRef 